MARIO BERGARA

Central Bank of Uruguay

and University of Uruguay

BARAK RICHMAN

University of California, Berkeley

PABLO T. SPILLER

University of California, Berkeley

\title{
Modeling Supreme Court Strategic Decision Making: The Congressional Constraint
}

This paper addresses the contradictory results obtained by Segal (1997) and Spiller and Gely (1992) concerning the impact of institutional constraints on the U.S. Supreme Court's decision making. By adapting the Spiller and Gely maximum likelihood model to the Segal dataset, we find support for the hypothesis that the Court adjusts its decisions to presidential and congressional preferences. Data from 1947 to 1992 indicate that the average probability of the Court being constrained has been approximately one-third. Further, we show that the results obtained by Segal are the product of biases introduced by a misspecified econometric model. We also discuss how our estimation highlights the usefulness of Krehbiel's model of legislative decision making.

\section{Introduction}

The Supreme Court's power as a policy maker is evident from the effort that politicians devote to the selection of justices. Recently, a debate has emerged over whether or not the Court's contribution to policy making can be understood without a comprehensive understanding of how justices interact with other political institutions and among themselves.

On one side of the debate lies the strategic school, whose modern form first emerged from the nonstrategic approach developed by Marks (1988). This camp has since moved on to develop simple but empirically implementable models of the separation of powers ${ }^{1}$ (Epstein and Walker 1995; Gely and Spiller 1990; Spiller and Gely 1992) and later to refine and extend the model to games within the Court (Epstein and Knight 1998; Schwartz 1992). ${ }^{2}$ The explicit assumption in all these models is that justices, like all economic actors, are forward-looking 
players with well-defined and stable policy preferences. In their interactions with other policy actors, justices are strategic; when formulating their actions, they consider the potential reactions of their policy competitors - namely Congress, the president, the agencies, and the lower courts. ${ }^{3}$ Thus, the ideological composition of Congress, the agencies, the lower courts, and the president's preferences can all be relevant factors in predicting the Court's final decisions.

On the other side of the debate lies the attitudinal approach to judicial decision making, which enjoys a long and distinguished history in political science. The central hypothesis in this approach is that justices make their decisions by relying exclusively on their individual ideological preferences. They are unmoved by the preferences of either their fellow justices or other political actors and thus do not act strategically. ${ }^{4}$ The attitudinal approach can be traced back to the work of Pritchett $(1941,1948)$ and Schubert (1965) and has continued in the research of Segal and Cover (1989), Segal and Spaeth (1993), and Segal et al. (1995). Employing a comprehensive dataset reflecting congressional and Supreme Court ideologies and Supreme Court decisions, Segal (1997) finds that individual justices act unconstrained by Congress's and the president's policy preferences and sincerely vote their policy preferences. His conclusion challenges the basic foundation of the strategic separation-of-powers model. In particular, it questions whether or not the results found by Spiller and Gely (1992), concerning the Supreme Court's decisions in the National Labor Relations Board cases, can be generalized to other domains of policy making. ${ }^{5}$

Like Spiller and Gely, Segal attempts to determine if the Supreme Court strategically adapts to the constraints imposed by the preferences of other relevant political actors and correspondingly adjusts its decisions. It is difficult to resolve such a debate employing contrasting datasets and empirical methodologies. Here, we move towards resolving such inconsistent results by employing the econometric model developed by Spiller and Gely (1992) to analyze Segal's data (1997). In doing so, we find that justices do adjust their decisions to presidential and congressional preferences. We also show that Segal's conclusions result, in part, from a misspecified econometric model that is biased against the finding of strategic behavior.

\section{Rational Choice Models}

Both the strategic and the attitudinal approaches to judicial decision making sharply contrast with the perspective employed in traditional legal studies. Whereas traditional legal scholarship looks to formulaic 
legal interpretations to predict Court outcomes, the attitudinal and strategic approaches emphasize the role of the justices' ideological preferences. Similar to microeconomic theory, which assumes that individuals have stable but differing preferences, these rational choice theories argue that justices have an assortment of stable but contrasting ideologies. When on the Court, justices vote on cases with the aim of enacting policies that best reflect their ideological preferences. In essence, justices' preferences can be characterized by a well-behaved ideological utility function that obtains a maximum at a particular policy outcome and decreases monotonically as outcomes move away from that maximum (the individual's ideal policy).

More specifically, the attitudinal approach posits that justices vote strictly according to their individual ideologies - no strategic or institutional considerations enter into justices' calculi. Decisions are unfiltered reflections of the Court's ideology and, accordingly, justices' ideologies should be the only significant predictors of Supreme Court rulings (Segal 1997; Segal and Cover 1989; Segal and Spaeth 1993).

The strategic approach departs from the attitudinal approach in the regard that it views justices as far-sighted individuals who are wary of their counterpart players in American policy making. Justices are assumed to hold a sophisticated understanding of both the legislative process and congressional policy preferences. Consequently, justices would not want to pass down a decision that would be overturned by an act of Congress if Congress would replace the decision with a policy that, in the view of a majority of the Court, led to an inferior outcome. Accordingly, the Court makes decisions that, in general, Congress would not overturn. ${ }^{6}$ Thus, the strategic approach incorporates congressional (and presidential) preferences as additional variables.

It is easy to imagine situations where the attitudinal and the strategic models would generate different predictions. Consider a scenario in which the Supreme Court can make decisions that implement policies located at any point along a continuous one-dimensional ideological spectrum, as is presented in Figure $1 .{ }^{7}$ The figure contains the ideal points of three justices $(A, B$, and $C)$ and those of the House $(H)$ and Senate $(S)$. For simplicity's sake, we assume that the preferences of the House and the Senate can be represented by single points in the ideological spectrum (perhaps the ideal point of each chamber's median voter) and we assume away the ability of the president to veto legislation. A majority of justices - who, according to the median voter theorem, are collectively represented by the median justice-would prefer the ideal point for justice $B$. Thus, the attitudinal model would predict that the policy outcome would be at justice $B$ 's ideal point. Forward-looking 
FIGURE 1

Three Justices $(A, B, C)$, the House $(H)$, and the Senate $(S)$

Along an Ideological Spectrum with a

Continuum of Policy Outcomes

$$
\begin{aligned}
& \text { Conservative--------A-----------------------B-----S----------H--------C-----Liberal } \\
& \text { Predicted Outcome: } \quad \mathrm{P}_{\mathrm{a}} \quad \mathrm{P}_{\mathrm{s}}
\end{aligned}
$$

Note: Attitudinal and strategic models generate different predictions, $\mathrm{P}_{\mathrm{a}}$ and $\mathrm{P}_{\mathrm{s}}$, respectively.

justices would realize, however, that the House and Senate would act together to replace such a policy outcome since there are several points along the policy spectrum that both $H$ and $S$ would prefer over the policy $B$. Justice $B$, supported by a majority of the justices, would thus prefer to pass down a decision that the House and Senate will not overturn but that is as close as possible to her ideal point. ${ }^{8}$ In this figure, such a point is the Senate's ideal point. Since the Senate prefers $S$ to all other outcomes, it will block any alternative policy proposal, so the Court's ruling is secure. In sum, the Court chooses to implement policy $S$ since it maximizes the utility of the Court's majority (represented by the ideal point of its median justice) subject to the constraints imposed by congressional preferences. ${ }^{9}$

The strategic model's prediction for the Court's decision falls weakly within the congressional Pareto set. ${ }^{10}$ Consequently, construction of that set is a critical element of the model since it functionally represents Congress's preferences. The Supreme Court's relationship with Congress is determined by where the median justice's ideal point is in relation to Congress's Pareto set. If the median justice's ideal point, which we hereafter call "the Court's ideal point" and represent with $S C_{i}$, lay outside Congress's Pareto set - which is the case in both Regime 1 and Regime 2, as shown in Figure 2 - then any decision that reflected the Court's sincere preferences would be overturned by Congress. Consequently, in these cases, the Court, if acting strategically, would pass decisions - such as $D_{1}$ or $D_{2}$ that lay within the congressional Pareto set but were as close to its ideal point as possible. If, however, the median justice's ideal point fell within Congress's Pareto set, as is the case in Regime 3, then the Court would be unconstrained and could vote its own preferences, i.e., its decisions would reflect the median justice's ideal point. Thus, under Regime 3, the attitudinal and strategic approaches yield the same predictions. 
FIGURE 2

Three Possible Supreme Court Ideal Points

Create Three Different Regimes, Each With Its Own Predicted Court Decision

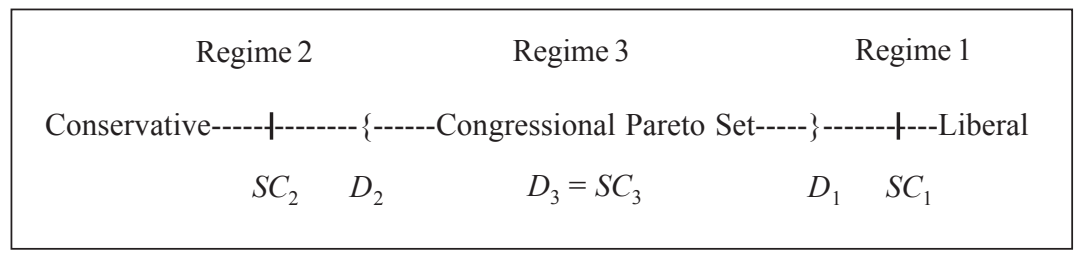

An important implication of this analysis is that if the strategic assumption is appropriate, then the final policy outcome depends, in equilibrium, on the preferences of a single political actor. In Regime 1, the Court's action is determined by the member of Congress who defines the most liberal end of the Pareto set; in Regime 2, action is determined by the member of Congress who defines the most conservative end of the set; in Regime 3, the outcome depends exclusively on the median justice's ideal point. Thus, only when the median justice is located within the Pareto set of Congress will the strategic approach predict that the court is unconstrained by politics. That is, only in Regime 3 will the attitudinal and the strategic approaches provide similar predictions concerning judicial decisions.

Empirical tests can, using this result, compare the appropriateness of the attitudinal and strategic models. Note that both models predict that the Court would vote its own preferences if the median justices' ideal point lay within Congress's Pareto set. If, however, the Court's ideal point lay outside the Pareto set, then the models would yield different predictions. The attitudinal model argues that the Court would continue to vote its sincere preferences (that is, the median justice's ideal point) while the strategic model forecasts a decision that would lie just within Congress's Pareto set. An empirical test of these differing hypotheses requires sound measurements for both congressional preferences and Supreme Court ideologies, as well as a model of the legislative process that maps out a compelling congressional Pareto set.

\section{Testing the Strategic versus the Attitudinal Approaches}

In this section, we develop the econometric model to estimate the determinants of Supreme Court decisions in statutory cases. ${ }^{11}$ We base this technique on the model devised by Spiller and Gely (1992), and we adapt it to analyze Segal's (1997) data. 
We begin by establishing a one-dimensional policy space, assigning all possible policy outcomes a value between $0-100$, where 0 represents the most conservative possible outcome and 100 represents the most liberal. The dependent variable is the Supreme Court's percent of pro-liberal decisions in statutory cases for a given year, and the explanatory variables are Congress's ideologies, guided and filtered by the legislative process, and the Court's ideology.

\section{Preferred Judicial Decisions}

It is reasonable to assume that there is positive correlation between an individual's ideology measure, whether he is a member of Congress or a Supreme Court justice, and his tendency to cast pro-liberal votes. We use this ideology measure to indicate a preference for a certain percent of pro-liberal judicial decisions for a given year. ${ }^{12}$ What is not reasonable, however, is to assume that a given measure of political preferences, like that formulated by the Americans for Democratic Action (ADA), maps exactly onto the preferred probability of a proliberal judicial decision for a given year. Were that the case, a legislator with an ADA score of, say, 60 , would optimally prefer a $60 \%$ probability for a pro-liberal outcome. ${ }^{13}$ This assumption, although testable, is too extreme. We therefore characterize the preferences of an individual, in either body, for pro-liberal judicial decisions with the equation

$$
E_{k a}^{*}=q+b P_{k a},
$$

where $E_{k a}^{*}$ represents individual $a$ 's most desired percent of pro-liberal decisions by the Court during time period $k, P_{k a}$ reflects that individual's ideology (with rising values for increasingly liberal ideologies) during that period, and $q$ and $b$ are parameters to be estimated. Since the working assumption is that the more liberal an individual's ideology, the higher the percent of pro-liberal Court decisions that individual will prefer, we should observe that $b>0$. Thus, our model estimates an individual's preferences for pro-liberal judicial decisions, which are unobservable, using their observable generic ideologies. Note that the parameters $q$ and $b$ are "structural" parameters, simply reflecting basic preferences. Since in Equation (1) we assume linearity, we can construct for any $b$ the whole game in the "probability" rather than the "political" space. The linear transformation allows us to treat representations of the probability or political spaces in the same dimension.

Let the actual percent of pro-liberal decisions during period $k$ be represented by $E_{k}$, and let individual $a$ be the decisive member of the 
House, Senate, or Supreme Court who, depending on the pertinent regime, determines the Court's outcome during that period. ${ }^{14}$ Then the relationship between the Court's judicial outcomes during a given period and the relevant individual's preferences is represented by

$$
E_{k}=E_{k a}^{*}+e_{k},
$$

where $a$ reflects the relevant political player in period $k$, and $e_{k}$ is an independently distributed error with a mean of zero.

Substituting Equation (1) into (2), we obtain

$$
E_{k}=q+b P_{k a}+e_{k},
$$

where $P_{k a}$ represents the (observable) political ideology of the relevant player during the given period. In order to accommodate Segal's data, which bundles Supreme Court decisions into yearly observations, we convert the periods in Equation (3) to individual years and arrive at

$$
E_{t}=q+b P_{t a}+e_{t},
$$

where $t$ identifies the year. The compositions of the Court and Congress usually vary year by year, but they are generally stable within a given year. Accordingly, the value of $P_{t a}$ should be stable throughout the year. ${ }^{15}$

\section{Regime Selection}

We now turn to the regime selection problem. Note again that $E_{t}$ is the Supreme Court's actual percent of pro-liberal decisions during year $t$, and $P_{t a}$ is the ideology measure of the relevant political player in year $t$. A key component of the strategic model is its identification of who the relevant political player is at each point in time. When the Supreme Court's ideal point is more liberal than all points within Congress's Pareto set (Regime 1), then the decisive player is the member of Congress who determines the uppermost boundary of the Pareto set. When the Court's ideal point is less liberal than all points within Congress's Pareto set (Regime 2), then the key player is the member of Congress who determines the lowermost boundary of the Pareto set. When the Court's ideal point lies within Congress's Pareto set (Regime 3), the Court is free to act on its true ideology and the median justice becomes the key player.

Consequently, each regime produces a different value for the political variable $P_{t a}$. When we substitute the different political variables into Equation (4), our econometric model articulates the three regimes as follows: 
(5a) Regime 1: $E_{t}=q+b^{*} \operatorname{Max}\left(H_{t}, S_{t}\right)+e_{t} \quad$ when $S C_{t}>\operatorname{Max}\left(H_{t}, S_{t}\right)$,

(5b) Regime 2: $E_{t}=q+b^{*} \operatorname{Min}\left(H_{t}, S_{t}\right)+\mathrm{e}_{t} \quad$ when $S C_{t}<\operatorname{Min}\left(H_{t}, S_{t}\right)$, and

(5c) Regime 3: $E_{t}=q+b * S C_{t}+e_{t} \quad$ when $\operatorname{Min}\left(H_{t}, S_{t}\right)<S C_{t}<\operatorname{Max}\left(H_{t}, S_{t}\right)$.

$H_{t}$ and $S_{t}$ represent the decisive players during year $t$ in the House and Senate, respectively.

\section{Comparing Congressional and Judicial Preferences}

As previously indicated, applying this model requires appropriate measures for both congressional and judicial preferences. We use ADA congressional ratings (despite their well-known problems) to reflect congressional ideologies, and we employ Segal's "constitutional scores" to reflect the Supreme Court's ideologies. ${ }^{16}$ Segal derives his constitutional scores by collecting data from Supreme Court decisions from 1947 to 1992 and then performing four steps. First, he selects the justices' votes only in non-unanimous constitutional cases. Second, he further refines his data by considering only cases where the Court decided a matter regarding civil liberties. Segal acknowledges that this step may limit his model's generality but explains that it adds a certain "cleanness" to his data, since civil liberties cases have easily definable conservative and liberal positions. Indeed, votes in civil liberties cases have proven to be accurate measures of ideological preferences and robust predictors of other judicial behavior (see Segal and Spaeth 1993). Third, Segal calculates the percent of pro-liberal votes each justice casts in these non-unanimous civil liberties cases for each year he or she is on the bench. Lastly, he performs a time-series regression on these annual pro-liberal percents and thus transforms a justice's "raw" liberal percent scores from each year into flattened values across years. These predicted values for each year then serve as his constitutional scores. ${ }^{17}$

Segal arrives at constitutional scores for individual justices that range from 5 (Rehnquist) to 93.3 (Douglas). ${ }^{18}$ Since these constitutional scores, like the ADA scores, are on a $0-100$ scale, it is tempting to place them, as Segal does, along the same dimension as the ADA scores and use this same dimension to compare Congress's and the Court's ideologies. This method would give a justice with a constitutional score of 25 the same ideological preferences as a member of Congress with an ADA score of 25. But the ADA and the constitutional scores are derived from fundamentally different data. ADA scores are a percent of pro-liberal votes cast by each member of Congress on 
nonconstitutional issues that are specifically selected by the ADA. ${ }^{19}$ On the other hand, Segal's constitutional scores are an index based on the percent of pro-liberal votes cast by each Supreme Court justice in constitutional cases. Furthermore, ADA ratings and Supreme Court votes have very different statistical distributions and come under very different institutional pressures, so their scores would naturally reflect ideology differently. Indeed, ADA scores are heavily bimodal, whereas Segal's constitutional scores are unimodal (see Snyder 1992). Making a direct comparison, as Segal does, requires that both scores be drawn from the same statistical distribution, which is not the case, or that both be translated into a common space, which is what we do here. ${ }^{20}$

The ADA and the averages of constitutional judicial votes are not easily comparable. In principle, one could imagine a transformation that brings one score into the dimension of the other (after all, both are liberal-conservative scores), but the selection of such a transformation is not an arbitrary decision. There is no reason why the final constitutional scores should span the entire ADA ideological spectrum from 0 to 100 instead of occupying a small slice from, say, 50 to 75 . For example, Segal transforms his raw scores by undertaking a linear transformation but, in principle, any arbitrary transformation is appropriate as long as it is "one to one." 21

On the other hand, which particular transformation of justices' scores onto the ADA scale is used has important econometric consequences. Recall that if a justice is to the left of the Pareto set, then the justice is in a different regime than those who are to the right of or within the Pareto set. So the transformation of constitutional scores onto the ADA scale affects both the regime in which each justice is located, which determines the value of the constraint variable, as well as the independent variables used to measure strategic behavior. Thus, inappropriately selecting the transformation will necessarily bias the results against a finding of strategic behavior. Segal acknowledges these difficulties and reports having consulted with public law scholars to confirm that the constitutional scores created an accurate ideological spectrum $(1997,36)$. Although approval from these scholars should indeed be comforting, and although there genuinely is no ex-ante method to conform the two scores to each other, the simple linear one-to-one translation invites a search for a more precise transformation.

We model the true Supreme Court preferences in the same dimension as congressional ADA scores as a latent variable, $\left(\overline{S C}_{t}\right)$, which is related to Segal's constitutional scores by the following equation:

$$
\overline{S C}=g+d * S C+u .
$$


Here, $S C$ represents Segal's constitutional scores, $g$ and $d$ are parameters to be estimated, and $u$ is a normally independently distributed error. $\overline{S C}$ is a latent variable that represents the ideal point of the justice in the ADA dimension and, as such, can be used in defining the relevant regimes in the econometric model. ${ }^{22}$ This equation essentially lets the data perform the transformation from judicial constitutional scores to ADA scores. So, while the constitutional scores still serve as a basis for determining the ideologies of Supreme Court justices, the model overcomes the basic problem of reconciling the constitutional scores with the ADA ratings by a stochastic transformation of constitutional scores into ADA ratings.

\section{A Switching Regression Model with Uncertain Separation Criteria}

The introduction of a latent variable to represent the Court's preferences in the ADA domain implies that we cannot perfectly observe the exact location of the Court's ideal point vis-à-vis congressional preferences. As a consequence, the switching-regimes model (5a-5c) has an unknown separation criteria. Let $s_{u}$ be the standard deviation of $u$ and $\Phi($.$) be the standard normal cumulative distribution function. { }^{23}$ We can then use Equations (5) and (6) to characterize the probabilities of observing Regimes 1,2 , and 3 in year $t\left(L_{1 t}, L_{2 t}\right.$, and $\left.L_{3 t}\right)$ so as to determine the likelihood function for the model (see Spiller and Gely 1992). These probabilities are respectively

$$
\begin{aligned}
L_{1 t}= & \operatorname{Pr}\left(\overline{S C}_{t}>\operatorname{Max}\left(H_{t}, S_{t}\right)\right)=1-\Phi\left[\left(\operatorname{Max}\left(H_{t}, S_{t}\right)-g-d^{*} S C_{t}\right) / s_{u}\right], \\
L_{2 t}= & \operatorname{Pr}\left(\overline{S C}_{t}<\operatorname{Min}\left(H_{t}, S_{t}\right)\right)=\Phi\left[\left(\operatorname{Min}\left(H_{t}, S_{t}\right)-g-d^{*} S C_{t}\right) / s_{u}\right], \text { and } \\
L_{3 t}= & \operatorname{Pr}\left(\operatorname{Min}\left(H_{t}, S_{t}\right)<\overline{S C_{t}}<\operatorname{Max}\left(H_{t}, S_{t}\right)\right)= \\
& \Phi\left(\left(\operatorname{Max}\left(H_{t}, S_{t}\right)-g-d^{*} S C_{t}\right) / s_{u}\right]-\Phi\left[\left(\operatorname{Min}\left(H_{t}, S_{t}\right)-g-d^{*} S C_{t}\right) / s_{u}\right] .
\end{aligned}
$$

The likelihood function for the model is then

$$
\begin{aligned}
L & =\prod_{t=1}^{T}\left(L_{1 k} \varphi_{1}+L_{2 k} \varphi_{2}+L_{3 k} \varphi_{3}\right), \\
\text { where } & \\
\varphi_{1} & =\left(1 / s_{e}\right) \varphi\left[\left(E_{t}-q-b^{*} \operatorname{Max}\left(H_{t}, S_{t}\right)\right) / s_{e}\right], \\
\varphi_{2} & =\left(1 / s_{e}\right) \varphi\left[\left(E_{t}-q-b * \operatorname{Min}\left(H_{t}, S_{t}\right)\right) / s_{e}\right] \text { and } \\
\varphi_{3} & =\left(1 / \sqrt{b^{2} s_{u}^{2}+s_{e}^{2}}\right) \varphi\left[\left(E_{t}-q-b(g+d * \overline{S C})\right) / \sqrt{b^{2} s_{u}^{2}+s_{e}^{2}}\right],
\end{aligned}
$$

with $\varphi($.$) representing the standard normal density function and s_{e}$ reflecting the standard deviation of the error term $e$. 
Our analysis applies standard maximum likelihood techniques to Equation (8), where $b$ is the coefficient that measures the significance of the ideology belonging to the relevant political player in each regime, and $g$ and $d$ reflect the transformation of judicial constitutional preferences into judicial ADA preferences. This analysis yields some important econometric and substantive implications. First, note that the ideology of an individual player - whether the median justice or key member of Congress - is significant in predicting the Court's decisions only under certain regimes. Second, our model implies that the coefficient $b$ should be positive, which is a refutable empirical hypothesis. If $b$ were estimated to be zero, then neither politics nor ideology would be significant in the Court's statutory decisions. The Court, essentially, would be making decisions based not on ideology but rather on the merits and specifics of the case. A nonpositive $b$ would reject not only the strategic but also the attitudinal approach, since both approaches require that justices cast votes based on their ideologies. Third, the model implies that if constitutional scores are a reasonable proxy for judicial preferences, then $d$ should be positive. Finally, the model endogenously determines probabilities of each regime (Equations 7a through 7c). Thus, if the probability of Regime 3 is close to one, then the strategic framework can be discarded in favor of the more parsimonious attitudinal model. Although we will not be able to reject the strategic model formally in this case, we would reject it de facto since it would lack both political (since the Court is never constrained) and empirical relevance. If, however, the probabilities of Regimes 1 or 2 are sufficiently distant from zero, then we can adequately test the strategic model, and a positive estimate for $b$ suggests that the strategic approach is superior to the attitudinal model. Indeed, the essence of the attitudinal model is that justices do not pay attention to institutional constraints, either because they are naïve or because the constraints are not binding. Positive probabilities for Regimes 1 and 2, combined with a positive estimate for $b$, reject both of these explanations.

Segal and Wang (2001) provide an overidentification test for the strategic model. Equations (5a) and (5b) imply that if the attitudinal model is false, then, conditional on being in Regime 1 or 2 , the probability of a pro-liberal decision should be independent of the Court's ideology. To confirm this speculation, we add a term to $(5 \mathrm{a})$ and $(5 \mathrm{~b})$ representing the Court's ideology, and we hypothesize that the coefficient for that ideology term is zero. In contrast, if the strategic model is false, then the coefficient of that term should be positive - and identical to the coefficient of the Court in Regime 3-and the coefficient of the political variable should be zero. This specification presents another test for both the attitudinal and strategic models. 


\section{Segal (1997) Revisited}

We apply our regime-switching methodology to the data used by Segal (1997). But before we discuss our findings, it is important to discuss Segal's (1997) approach.

The core of Segal's test of the strategic approach is an econometric analysis of individual justices' votes on nonconstitutional cases for the period 1947-92. His framework is based on the construction of a constraint variable that is supposed to measure whether or not a justice is constrained from voting her own preferences when casting a vote. The variable is defined by the following equation:

$$
\text { Constraint }=\left\{\begin{array}{lll}
\operatorname{Max}-S C_{i} & \text { if } & S C_{i}>\operatorname{Max} \\
M i n-S C_{i} & \text { if } & S C_{i}<\operatorname{Min} \\
0 & \text { if } & \operatorname{Min}>S C_{i}>\operatorname{Max}
\end{array} .\right.
$$

Max is the upper (most liberal) boundary of Congress's Pareto set, Min is the lower (most conservative) boundary, and $S C_{i}$ is justice $i$ 's constitutional score.

Segal's claim is that the constraint variable reflects the degree to which justices are constrained by Congress's ideologies. He posits that an acceptable test of the strategic model is whether or not the constraint variable is statistically significant in predicting justices' votes on statutory cases. The regression model Segal uses is represented by Equation (10):

$$
P L=a+p * \text { Constraint }+e .
$$

Here, $P L$ is the probability of casting a pro-liberal vote on a statutory case, $a$ and $p$ are parameters to be estimated, and $e$ is an error term. Segal argues that if the strategic model holds, then the parameter $p$ should be positive and statistically significant.

Although intuitively feasible, this approach has methodological flaws that bias the results toward a finding of statistical insignificance of the $p$ coefficient. First, the construction of the constraint set is inappropriate: even though the position of the justice in relation to the Pareto set may be constant, changes in the justice's preferences influence the constraint variable, thus biasing the coefficient of $p$ towards zero. ${ }^{24}$ Second, the unit of analysis is the individual judge when the strategic theory only has predictions for the median judge, thus again biasing the coefficient of $p$ toward zero. ${ }^{25}$ Third, the constraint variable is built by 
directly comparing ADA ratings to judicial preferences, which, as we discussed before, introduces a serious measurement error, potentially biasing $p$ toward zero.

Finally, and most problematic, Segal uses various congressional models - the Committee Gatekeeping model (CGK), the Multiple Veto model (MV), and the Party Caucus model (PC) - to derive congressional Pareto sets. Unfortunately, given his preference symmetry assumption, these models tend to generate Pareto sets that extend beyond the $0-100$ range. Recall that the whole ideological space must lie strictly in the $0-100$ range; the excessive boundaries of these legislative models point to some important failings. ${ }^{26}$ (See Figures A1-A3 in Appendix I for the political constraints imposed by the CGK, MV, and PC models.) This observation has several implications. First, since Segal's analysis only examines the voting behavior of justices that lie outside the constraint set, an overly broad constraint set will exclude some moderate justices who may act strategically. Instead, his analysis only captures the "extreme" justices, who are unlikely to be the median justice and thus will vote their sincere preferences even according to the strategic theory. Second, the method may be assigning observations to the wrong regimes and hence using improperly measured righthand-side variables. ${ }^{27}$ Both of these problems - which are present for each of the three legislative models - bias the estimate coefficient of $p$ toward zero.

A particularly compelling alternative to the legislative models discussed above has been offered by Krehbiel (1998). Building upon his prior emphasis on the power of the floor, Krehbiel constructs a Pareto set that stresses the roles of the presidential veto and the Senate's filibuster. His model views the veto and the filibuster as the two chief hurdles to congressional action, and any legislative initiative must muster sufficient support to overcome both. This Filibuster-Veto (F-V) model is readily translated into a one-dimensional policy space, and the impacts of both the presidential veto and the filibuster can be modeled.

A bill can override a presidential veto if it has support from twothirds of both the House and the Senate, so Congress would confidently be able to overturn Supreme Court decisions if two-thirds of members of both chambers preferred an alternative policy. This fraction is the relevant boundary when Congress tries to overturn a decision that the president supports and is defined by the member at 67 th percentile of the ideological position shared by the president. The filibuster boundary is similarly delimited, but only for the Senate. Since threefifths of the Senate is required to bring cloture to a debate, any legislative action that has the president's support must also receive support from 
three-fifths of the Senate. It follows that the filibuster's boundaries are defined by the senator at the 40th percentile with the ideological position opposite the president. The Pareto sets generated by the F-V models for the period under consideration, 1947-92, have more reasonable ranges than the three other legislative models discussed here, and, as a consequence, the F-V model becomes a reasonable one on which to test the attitudinal versus the strategic hypotheses. We add Krehbiel's framework to those selected by Segal in our testing of the attitudinal and strategic approaches.

\section{Data and Empirical Results}

Our model requires measurements reflecting congressional preferences, Supreme Court preferences, and Supreme Court decisions. For congressional preferences, we use the pro-liberal scores computed every year by the ADA. ${ }^{28}$ For each legislative model, we then determine the bounds for the congressional Pareto set. For Supreme Court preferences, we use the constitutional scores Segal assigns to individual Supreme Court justices, which reflect the percent of pro-liberal votes a justice casts each year in constitutional cases..$^{29}$ Our model is designed to predict the Supreme Court's percent pro-liberal decisions in statutory cases for a given year. In the same way that we use the median justice's constitutional scores to measure the Court's ideology, we employ the median justice's percent pro-liberal votes as a proxy for the Court's statutory decisions. ${ }^{30}$ From these data, our model employs four chief variables: the median justice's constitutional scores that reflect her ideological preferences (and thus the ideology of the Court), two congressional constraint values representing the upper and lower boundaries of Congress's Pareto set, and the median justice's percent pro-liberal votes in statutory cases. The first three parameters are independent and explanatory variables, and the lattermost is the dependent variable. ${ }^{31}$

Our analysis begins with ordinary least-squares regressions using the political constraints defined by Krehbiel's Filibuster-Veto model, the Committee Gatekeeping model, the Multiple Veto model, and the Party Caucus model.

One result that carries across all models is that the Court's ideology has a significant impact on its decisions, a finding consistent with both the attitudinal and strategic approaches. The effect of politics is still unclear, but recall that ordinary least squares is an inappropriate method for testing for strategic behavior. OLS presumes that the three potentially relevant political players - the median justice and the two determinative members of Congress - all simultaneously influence the 
TABLE 1

Linear Probability Models across Alternative Legislative Models ${ }^{a}$

(t-statistics in parentheses)

\begin{tabular}{lcccc}
\hline Variable & F-V & CGK & MV & PC \\
\hline Constant & 18.51 & 16.79 & 8.87 & 9.75 \\
& $(2.44)$ & $(2.44)$ & $(1.09)$ & $(1.35)$ \\
SC & 0.71 & 0.72 & 0.68 & 0.67 \\
& $(6.92)$ & $(7.47)$ & $(6.90)$ & $(7.01)$ \\
Max & 0.03 & 0.21 & 0.06 & 0.07 \\
& $(0.19)$ & $(0.26)$ & $(1.15)$ & $(1.18)$ \\
Min & 0.18 & -0.15 & -0.03 & 0.05 \\
& $(-1.02)$ & $(-0.96)$ & $(-0.48)$ & $(0.64)$ \\
$\mathrm{R}^{2}$ & 0.58 & 0.58 & 0.59 & 0.59 \\
F-stat. & 19.65 & 19.48 & 19.93 & 20.25 \\
Standard Error & 0.0874 & 0.0877 & 0.0871 & 0.0867 \\
Akaike IC & & & & \\
Number of Observations: 46 & -83.69 & & -84.00 & -84.43 \\
\hline
\end{tabular}

${ }^{a}$ We normalized the data by dividing all of the values by 100 ; this step was necessary in order to perform the maximum likelihood function. Normalizing does not at all affect the estimated coefficients or our substantive results, but it does change the intercepts and the standard error. For example, an intercept (constant) value of 0.185 represents a score on the ADA scale of 18.5.

${ }^{b}$ The Akaike Information Criterion [(AIC) Akaike 1974; Harvey 1981] is commonly used to compare non-nested models fit to the same data. The AIC, for maximum likelihood estimators, is computed as $-2 \ln (\mathrm{L})+2 \mathrm{k}$, where $\mathrm{L}$ is the value of the likelihood function and $\mathrm{k}$ is the number of parameters to be estimated. For OLS estimations, the AIC is computed as $\mathrm{N}\left[\log \left(2 \pi \sigma^{2}\right)+1\right]+2(\mathrm{k}+1)(\mathrm{Chi}$ and Russell 1999). The model with the smaller information criterion is said to fit the data better.

Court's outcomes. Consequently, the measurement of political constraints (which, incidentally, is diluted into two separate OLS coefficients) is for constraints throughout the period 1947-92, including those years when the Court is in Regime 3. This simultaneous analysis biases the parameters toward zero. 
The strategic approach, however, requires switching regressions and, in particular, switching regressions with uncertain separation criteria. Thus, we now discuss the results of the regime-switching econometric methodology described in the section above. Table 2 contains the results for the maximum likelihood estimation applied to each of the four legislative models. ${ }^{32}$

Table 2 shows that both ideology and politics matter, as the parameters $d$ and $b$ are highly significant. ${ }^{33}$ In particular, for a 10-point increase in the relevant player's ideological score (ADA for a member of Congress and imputed ADA score for the median justice), the proliberal percent of annual decisions increases about $3 \%$ for the Multiple Veto model and $6 \%$ for the other models. ${ }^{34}$ From this finding, we conclude that the ideologies of the relevant players across regimes is significant, not just the Court's ideology. In other words, when in Regime 1 or 2 , the Court does seem to adhere to the relevant political constraints. ${ }^{35}$ Moreover, these models all fit the data better than the respective OLS estimates presented in Table 1. Indeed, the Akaike Information Criterion shows lower values for the switching regression models in Table 2 than for the OLS models of Table 1.

Comparison of the results from the F-V and other legislative models reveals further insights. All models measure the total effect of ideology, $d^{*} b$, to be significant, but the $\mathrm{F}-\mathrm{V}$ model ascribes more of this effect to the political variable. Meanwhile, the Multiple Veto, far more than any of the other models, generates a high value for the ideology parameter, $d$, and a low value for the political parameter, $b$. The reason for this imbalance is that the Multiple Veto model generates far too many observations that violate the $0-100$ ideological range constraint, thus grossly overstating congressional gridlock. As a consequence, it would overestimate the likelihood that a Supreme Court would have its ideal point within Congress's Pareto set, i.e., in Regime 3, and thus predict that the Court can act unconstrained. Consequently, the predictive power that the Multiple Veto model ascribes to ideology may be overstated by the $S C$ variable and understated by the political constraints.

For the F-V model, alternatively, the maximum likelihood technique estimates that the Court is more frequently constrained by Congress. Our results indicate that the probability the Court is constrained under the F-V model is, on average, $33 \%$, compared to $18 \%$ under the Multiple Veto model or 14\% under the Party Caucus model. The CGK model, which has fewer observations that violate the $0-100$ constraint, predicts a $29 \%$ probability of constrained decision making. ${ }^{36}$ These results are significant because the F-V and CGK models, with fewer 
TABLE 2

The Econometric Model

Maximum Likelihood Estimation

(t-statistics in parentheses)

\begin{tabular}{|c|c|c|c|c|c|}
\hline Parameter & Variable & $\mathrm{F}-\mathrm{V}$ & CGK & MV & $\mathrm{PC}$ \\
\hline$g$ & CONSTANT & $\begin{array}{c}-12.85 \\
(-0.82)\end{array}$ & $\begin{array}{c}-15.65 \\
(-0.70)\end{array}$ & $\begin{array}{l}-60.97 \\
(-1.46)\end{array}$ & $\begin{array}{c}-11.53 \\
(-0.84)\end{array}$ \\
\hline$d$ & $\mathrm{SC}$ & $\begin{array}{c}1.10 \\
(3.60)\end{array}$ & $\begin{array}{c}1.22 \\
(2.64)\end{array}$ & $\begin{array}{c}2.69 \\
(3.01)\end{array}$ & $\begin{array}{c}1.37 \\
(3.48)\end{array}$ \\
\hline$q$ & CONSTANT & $\begin{array}{c}0.23 \\
(3.87)\end{array}$ & $\begin{array}{c}0.25 \\
(3.16)\end{array}$ & $\begin{array}{c}0.32 \\
(5.83)\end{array}$ & $\begin{array}{c}0.21 \\
(3.55)\end{array}$ \\
\hline$b$ & POLITICS & $\begin{array}{c}0.66 \\
(4.42)\end{array}$ & $\begin{array}{c}0.60 \\
(3.38)\end{array}$ & $\begin{array}{c}0.28 \\
(3.72)\end{array}$ & $\begin{array}{c}0.55 \\
(3.59)\end{array}$ \\
\hline$s_{e}$ & & $\begin{array}{l}0.0531 \\
(2.54)\end{array}$ & $\begin{array}{l}0.0569 \\
(2.31)\end{array}$ & $\begin{array}{l}0.0553 \\
(2.57)\end{array}$ & $\begin{array}{c}0.0834 \\
(11.71)\end{array}$ \\
\hline$s_{u}$ & & $\begin{array}{r}0.113 \\
(3.08)\end{array}$ & $\begin{array}{r}0.119 \\
(2.92)\end{array}$ & $\begin{array}{r}0.230 \\
(2.42)\end{array}$ & $\begin{array}{c}0.019 \\
(1.75)\end{array}$ \\
\hline & Log-Likelihood & 50.26 & 48.75 & 50.97 & 48.68 \\
\hline & Akaike IC & -88.52 & -85.50 & -89.94 & -85.36 \\
\hline & Pr. Regime 1 & 0.09 & 0.12 & 0.11 & 0.08 \\
\hline & Pr. Regime 2 & 0.24 & 0.17 & 0.07 & 0.06 \\
\hline & Pr. Regime 3 & 0.67 & 0.71 & 0.82 & 0.86 \\
\hline
\end{tabular}

Number of Observations: 46

observations violating the $0-100$ range, put a much more rigorous test to the hypothesis for strategic behavior. Because the estimated $b$ parameters are still so highly significant (and, in fact, statistically different than the one estimated under the MV model and slightly higher than for the PC version), the conclusion that the Court thinks strategically cannot be rejected. 
FIGURE 3

Predicted SC and F-V Constraints

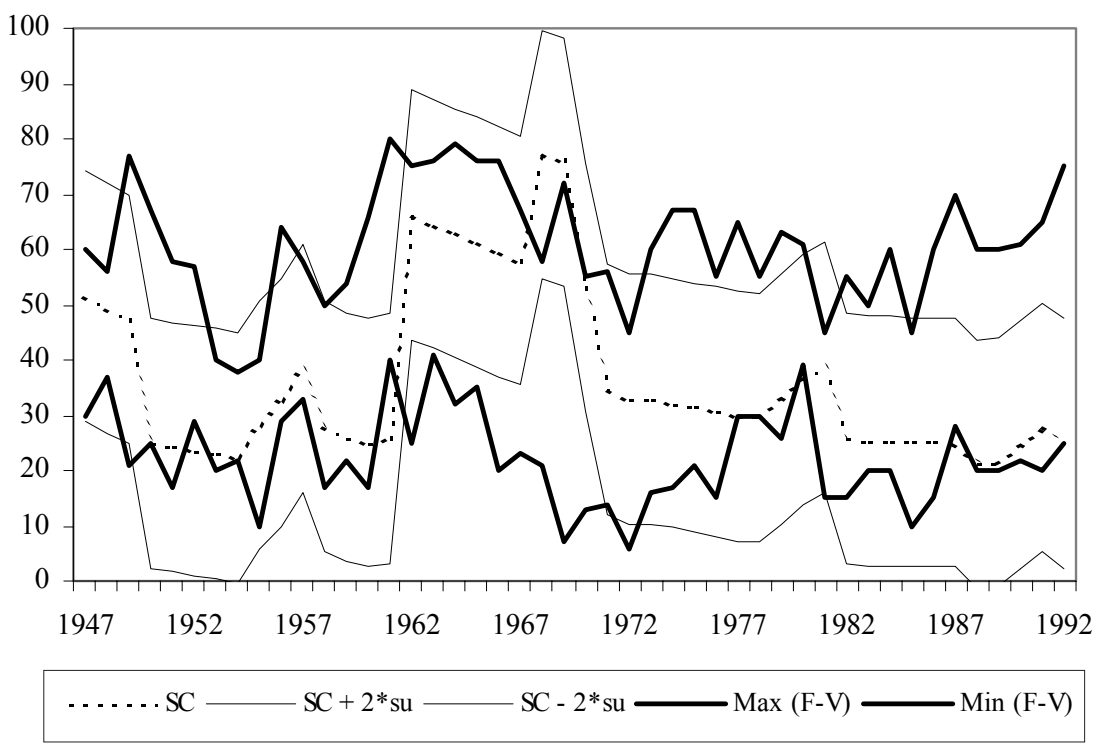

In Figure 3, we plot the Max $(F-V)$ and $\operatorname{Min}(F-V)$ boundaries of Congress's Pareto set with the Court's predicted ideal point. Similar information for the other three models is presented in Figures A1-A3 in Appendix I. ${ }^{37}$ Figure 3 shows that the Court's predicted $\overline{S C}$, as computed by the F-V estimation, generally rises and falls with congressional preferences, which explains why the average probability for Regime 3 is about two-thirds. Note, however, that there are also periods when the Court's ideology presses against Congress's constraints. Specifically, the Court was close to the conservative boundary of the congressional Pareto set through most of the 1950s, indicating a significant probability that it was in Regime 2 during that period. The Court then became more liberal in relation to Congress in the late 1960s, thus suggesting a significant probability that it was in Regime 1. For the late 1980s and early 1990s, the Court again approached the conservative boundary of the congressional Pareto set and again produced a growing likelihood that it was in Regime 1. Thus, although the Court appears to be mostly unconstrained throughout the 1947-92 period, it actually underwent periods when it was likely to be under Congress's political constraints. ${ }^{38}$ 
FIGURE 4

Probabilities of Regimes 1, 2, and 3 under F-V Model

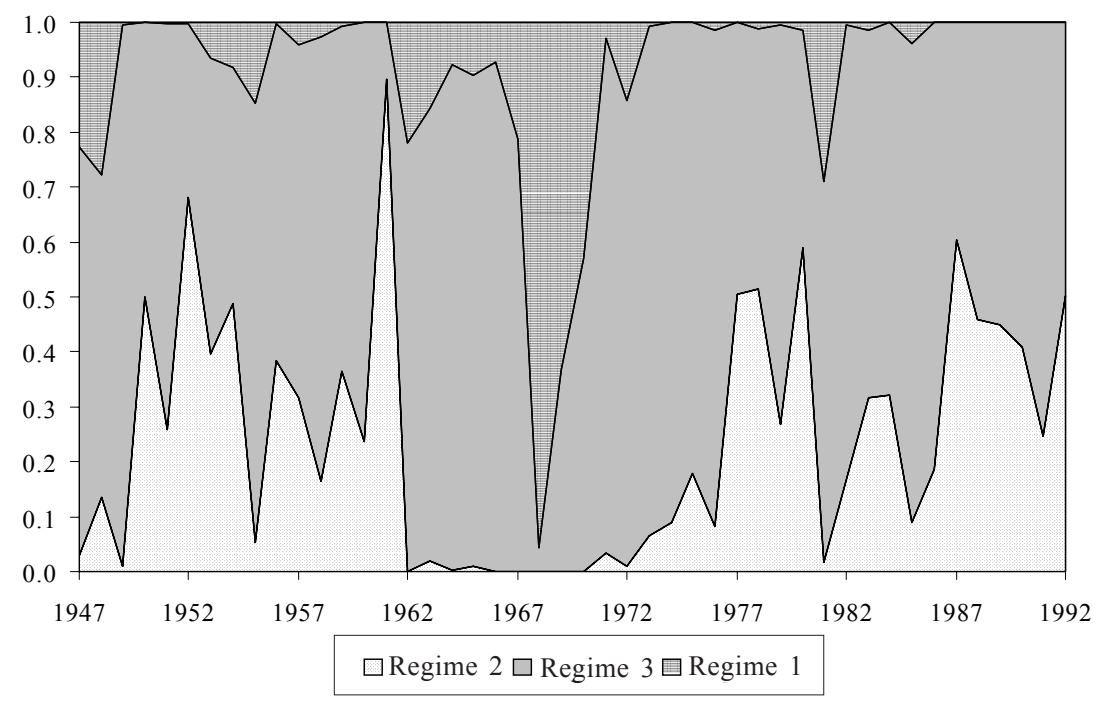

Figure 4 provides the estimated probabilities of each regime for each year (always summing to 1.0), thereby illustrating this point. As the predicted $\overline{S C}$ approaches the upper Pareto boundary, as it did in the late 1960 s, the probability of Regime 1 increases. Similarly, as $\overline{S C}$ approaches the lower Pareto boundary, as it did throughout the 1950s and 1980s, the probability of Regime 2 increases. Consequently, the results indicate that the likelihood of each regime is sufficiently robust as to pose a real test to the econometric model, and for several years, the probabilities of Regimes 1 and 2 were high enough to pose political constraints on the Court.

An additional feature of Krehbiel's model is that it gives some support to Segal's linear transformation of judicial preferences into the 0-100 ADA scale. Under the maximum likelihood estimation, the F-V model generates a value for the parameter $d$ that is fairly close to 1 , thus giving balanced weight to the original constitutional scores and the ADA ratings. ${ }^{39}$ So, although methodologically suspect, Segal's direct comparison of justices constitutional scores and legislators' ADA ratings receives support from the F-V estimation. ${ }^{40}$

In sum, results from both Tables 1 and 2 illustrate that ideology matters because the justices' ideologies substantially influence their final decisions. The results in Table 2 show that politics also matter, since the political constraints contribute substantially to predicting the Court's outcomes and indicate that justices exercise their ideology in a 
TABLE 3

Model with Overidentification Parameters

Maximum Likelihood Estimation

( $t$-statistics in parentheses)

\begin{tabular}{|c|c|c|c|c|c|}
\hline Parameter & Variable & $\mathrm{F}-\mathrm{V}$ & CGK & MV & $\mathrm{PC}$ \\
\hline$g$ & CONSTANT & $\begin{array}{c}-16.40 \\
(-0.81)\end{array}$ & $\begin{array}{l}-0.938 \\
(-0.19)\end{array}$ & $\begin{array}{l}-6.38 \\
(-0.57)\end{array}$ & $\begin{array}{c}-4.41 \\
(-0.70)\end{array}$ \\
\hline$d$ & $\mathrm{SC}$ & $\begin{array}{c}1.43 \\
(3.64)\end{array}$ & $\begin{array}{c}0.83 \\
(5.51)\end{array}$ & $\begin{array}{c}0.94 \\
(3.27)\end{array}$ & $\begin{array}{c}0.95 \\
(5.61)\end{array}$ \\
\hline$q$ & CONSTANT & $\begin{array}{c}0.28 \\
(6.53)\end{array}$ & $\begin{array}{c}0.19 \\
(3.15)\end{array}$ & $\begin{array}{c}0.25 \\
(3.15)\end{array}$ & $\begin{array}{c}0.22 \\
(3.22)\end{array}$ \\
\hline$b_{3}$ & IDEOLOGY REGIME 3 & $\begin{array}{c}0.32 \\
(3.06)\end{array}$ & $\begin{array}{c}0.80 \\
(4.13)\end{array}$ & $\begin{array}{c}0.67 \\
(2.86)\end{array}$ & $\begin{array}{c}0.71 \\
(3.70)\end{array}$ \\
\hline$s_{u}$ & & $\begin{array}{c}0.15 \\
(2.95)\end{array}$ & $\begin{array}{c}0.11 \\
(5.29)\end{array}$ & $\begin{array}{c}0.13 \\
(2.75)\end{array}$ & $\begin{array}{c}0.11 \\
(3.82)\end{array}$ \\
\hline$s_{e}$ & & $\begin{array}{c}0.04 \\
(5.17)\end{array}$ & $\begin{array}{c}0.01 \\
(3.42)\end{array}$ & $\begin{array}{c}0.01 \\
(1.98)\end{array}$ & $\begin{array}{c}0.01 \\
(2.10)\end{array}$ \\
\hline$b_{1 / 2}$ & POLITICS REGIMES $1 \& 2$ & $\begin{array}{c}0.45 \\
(2.40)\end{array}$ & $\begin{array}{c}-0.93 \\
(-15.44)\end{array}$ & $\begin{array}{l}-0.98 \\
(-6.24)\end{array}$ & $\begin{array}{l}-1.02 \\
(-9.81)\end{array}$ \\
\hline$c_{1 / 2}$ & IDEOLOGY REGIMES $1 \& 2$ & $\begin{array}{c}0.13 \\
(0.98)\end{array}$ & $\begin{array}{c}1.58 \\
(6.50)\end{array}$ & $\begin{array}{l}1.52 \\
(5.31)\end{array}$ & $\begin{array}{c}1.54 \\
(5.86)\end{array}$ \\
\hline & Log-Likelihood & -51.98 & -57.47 & -56.59 & -57.98 \\
\hline & Chi-Square Test & 3.44 & & 11.23 & 18.60 \\
\hline & Pr. Regime 1 & 0.27 & 0.06 & 0.01 & 0.03 \\
\hline & Pr. Regime 2 & 0.14 & 0.15 & 0.08 & 0.17 \\
\hline & Pr. Regime 3 & 0.59 & 0.79 & 0.91 & 0.80 \\
\hline
\end{tabular}

sophisticated and strategic manner. Furthermore, Congress imposes palpable political constraints on the Court, and the constraints derived from Krehbiel's model and, to a lesser degree, the CGK model seem to capture the political game more than the other models discussed.

Table 3 provides the results of estimating the model with the overidentification parameters suggested by Segal and Wang (2001). Table 3 shows that for the F-V model the overidentification restrictions cannot be rejected at standard significance levels. ${ }^{41}$ Indeed, the parameter $c_{1 / 2}$, which reflects the impact of the Court ideology in Regimes 1 and 2, is statistically insignificant and $b_{1 / 2}$, which reflects the role of politics in Regimes 1 and 2, is not statistically different from $b_{3}$, the parameter for 
ideology in Regime 3. Thus, for the F-V model, the findings fail to reject the overidentification restrictions. These restrictions, however, can be rejected at the $1 \%$ level for the other three models.

Under closer examination, Table 3 provides further evidence of the misspecification of the CGK, MV, and PC models. First, the coefficients of politics in Regimes 1 and 2 are all negative, large, and significantly different from zero. The attitudinal model would predict them to be zero, whereas the strategic approach would predict them to be positive. Second, the estimated ideology parameters for Regimes 1 and 2 are all positive, highly significant, and much larger than the ideology parameter for Regime 3, yet the attitudinal model predicts that the ideology parameters for each regime should be the same and the strategic approach predicts them to be statistically insignificant. Finally, as to be expected given their large Pareto sets, the three regimes provide small estimates of probabilities for Regimes 1 and 2 .

In sum, the results reported in Table 3 fail to provide support to the attitudinal model. Although estimates under the CGK, MV, and PC models reject the overidentification restrictions, they fail to reject those restrictions in the way that the attitudinal model predicts (i.e., the coefficient of $b_{1 / 2}$ should be zero, which it is not, and the coefficients $b_{1 / 2}$ and $b_{3}$ should be equal, which they are not). On the other hand, the F-V model fails to reject the overidentification restriction, and the resulting parameters under this model are all as expected. We find these results to lend strong support both to the superiority of the strategic model over the attitudinal model and to the superiority of the F-V legislative model over the models used by Segal (1997).

\section{Conclusions}

While the journey to develop accurate predictions for Supreme Court decisions does not end here, this paper supports a sophisticated understanding of the Court's decision making, one where justices anticipate possible congressional action and adjust their actions accordingly.

The results within this paper reconcile, in a way, the long-running dispute between the attitudinal and the strategic approaches. First, we show that justices' ideologies do matter. Second, we show that the Court is often, but not always, constrained by Congress and the extent to which the Court is constrained by politics varies significantly over time. And third, when the Court is constrained, it seems to respond strategically. Considering the numerous important policy debates that engage our branches of government, we think applying this approach to other political games to understand how different political players exercise their authority and how policy outcomes emerge offers a rich research agenda. 
Mario Bergara is Director, Unidad Reguladora de Servicios de Comunicaciones (URSEC), Uruguay 988, CO 11300, Montevideo, Uruguay, Professor of Economics, University of Uruguay, and Senior Economist, Central Bank of Uruguay. Barak Richman is a Ph.D. student in Business and Public Policy, Haas School of Business, University of California-Berkeley and is currently a law clerk for Judge Bruce M. Selya, Federal Courthouse Room 311, One Exchange Terrace, Providence, RI 02903. Pablo T. Spiller is the Joe Shoong Professor of International Business and Public Policy, Haas School of Business, University of California- Berkeley, Berkeley, CA 947201900 and serves as Special Advisor, Bureau of Economics, Federal Trade Commission.

\section{APPENDIX I}

The computed values for the Court arising from the other legislative models are presented in Figures A1, A2, and A3. As in Figure 3, the interval [SC-2s $\left.s_{u}, S C+2 s_{u}\right]$ is also plotted, where $s_{u}$ is the standard deviation of $u$. This step is to capture the likely range of values for $S C$.

Figures A1, A2, and A3 illustrate the problems with the other three legislative models. Specifically, the models construct Pareto sets that reach beyond the feasible 0-100 scale and, as a consequence, tend to impose no palpable constraints on the Supreme Court. (In some instances, Court ideological scores also violate the $0-100$ restriction.) The Multiple Veto and Party Caucus models are especially problematic. The Committee Gatekeeping model only briefly extends beyond the $0-100$ range and generally imposes reasonable constraints. This model, however, reflects congressional preferences as being rather chaotic in relation to the Supreme Court's ideology, whereas it is striking how fluidly the Supreme Court's preferences match the flow of F-V constraints. The Committee Gatekeeping model also imposes constraints of very different "widths" during different years.

FIGURE A1

Committee Gatekeeping Model, Predicted SC Scores

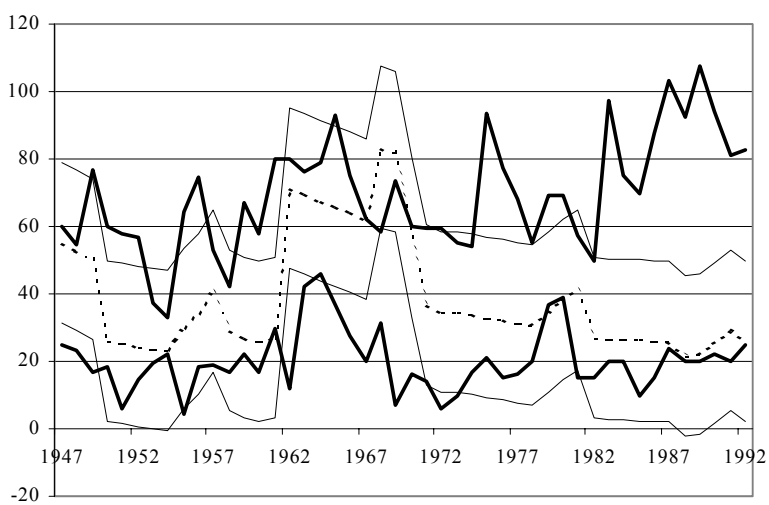

- - - Predicted $\mathrm{SC} \sim \longrightarrow \mathrm{SC} \sim+2 * \mathrm{su} \longrightarrow \mathrm{SC} \sim-2 * \mathrm{su} \rightleftharpoons$ High $(\mathrm{CGK}) \longrightarrow$ Low $(\mathrm{CGK})$ 
Predicted SC Score-Multiple Veto Model

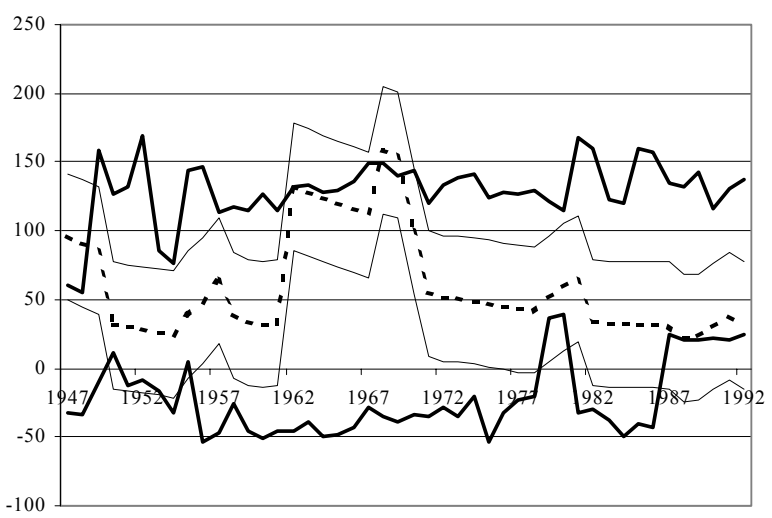

- - - Predicted $\mathrm{SC} \sim-\mathrm{SC} \sim+2 * \mathrm{su} \longrightarrow \mathrm{SC} \sim-2 * \mathrm{su}=$ High (MV) $\longrightarrow$ Low (MV)

FIGURE A3

Party Caucus Model, Predicted SC Scores

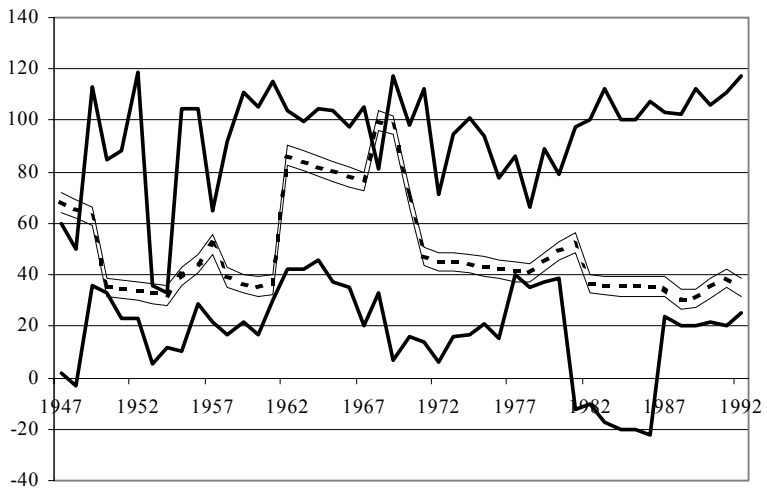

- - - Predicted $\mathrm{SC} \sim \longrightarrow \mathrm{SC} \sim+2 * \mathrm{su} \longrightarrow \mathrm{SC} \sim-2 * \mathrm{su} \longrightarrow$ High $(\mathrm{PC}) \quad$ Low $(\mathrm{PC})$ 


\section{APPENDIX II}

Segal (1997) also employs the Segal-Cover (1989) scores as an alternative measurement for the Supreme Court's ideological preference. Our preceding discussion centers on the constitutional scores since the Segal-Cover scores have been shown to have important measurement errors (Epstein and Mershon 1996). Nonetheless, we performed the same econometric analysis using the Segal-Cover scores to impute the Supreme Court's ideal point, and the results again show a strong influence of congressional preferences on Supreme Court decisions. We first report in Table A1 a linear regression of the Court's percent pro-liberal decisions in statutory cases using the Court's ideal point, determined by Segal-Cover scores, and the congressional constraints, as determined by each of the four models for the legislative process.

Like the results with the constitutional scores, the coefficient for the Supreme Court's ideology is significant in all four regressions, further weakening the notion of the Court as legalistic decision makers. In addition, like the earlier results, Congress's constraints generally appear insignificant. Although the high constraint variables appear to be significant in the F-V and Multiple Veto models, the low constraint variables are in the wrong direction. The CGK and Party Caucus models generate similarly unreliable results. The F-statistics and log-likelihood results also indicate that these linear regressions do a poor job of explaining the variance of the Supreme Court's statutory decisions compared to the corresponding regressions that use the constitutional scores.

TABLE A1

Linear Probability Models across Alternative Political Models, Using Segal-Cover

(t-statistics in parentheses)

\begin{tabular}{lcccc}
\hline Variable & F-V & CGK & MV & PC \\
\hline CONSTANT & 0.292 & 0.345 & 0.279 & 0.340 \\
& $(2.93)$ & $(4.18)$ & $(2.85)$ & $(4.11)$ \\
SC & 0.12 & 0.15 & 0.13 & 0.12 \\
& $(3.20)$ & $(3.56)$ & $(3.09)$ & $(3.00)$ \\
Max & 0.38 & 0.13 & 0.13 & 0.11 \\
& $(2.08)$ & $(1.10)$ & $(1.79)$ & $(1.29)$ \\
Min & -0.26 & 0.14 & -0.06 & 0.12 \\
& $(-1.15)$ & $(0.73)$ & $(-0.91)$ & $(1.18)$ \\
R & 0.28 & 0.25 & 0.28 & 0.27 \\
F-statistic & 5.58 & 4.72 & 5.52 & 5.16 \\
Standard Error & 0.115 & 0.117 & 0.115 & 0.116 \\
Akaike IC & -58.44 & -56.85 & -58.44 & -57.64 \\
\multicolumn{2}{l}{ Number of Observations: 46} & & & \\
\hline
\end{tabular}




\section{Supreme Court Decision Making}

The results of estimating the regime-switching econometric model with the SegalCover scores to test strategic behavior by the Supreme Court are shown in Table A2. Here, all four models show the political constraints coefficient to be highly significant. Similarly, the Court's ideology is also significant, although less so.

In sum, the Segal-Cover scores reveal a Supreme Court that is even more constrained than the one whose ideology measure was derived from its constitutional decisions, further providing support to the strategic approach. Thus, independent of the measure used to estimate the ideological preferences of the Court, congressional preferences are shown to have a marked effect on the Supreme Court's decisions.

\section{TABLE A2}

The Econometric Model, Using Segal-Cover Maximum Likelihood Estimates

(t-statistics in parentheses)

\begin{tabular}{|c|c|c|c|c|c|}
\hline Parameter & Variable & $\mathrm{F}-\mathrm{V}$ & CGK & MV & $\mathrm{PC}$ \\
\hline$g$ & CONSTANT & $\begin{array}{l}30.0 \\
(5.39)\end{array}$ & $\begin{array}{l}34.9 \\
(5.95)\end{array}$ & $\begin{array}{l}52.7 \\
(3.77)\end{array}$ & $\begin{array}{l}60.0 \\
(7.61)\end{array}$ \\
\hline$d$ & $\mathrm{SC}$ & $\begin{array}{c}0.30 \\
(2.26)\end{array}$ & $\begin{array}{c}0.29 \\
(1.86)\end{array}$ & $\begin{array}{c}0.47 \\
(1.97)\end{array}$ & $\begin{array}{c}0.32 \\
(1.82)\end{array}$ \\
\hline$q$ & CONSTANT & $\begin{array}{l}27.2 \\
(5.64)\end{array}$ & $\begin{array}{l}27.8 \\
(4.18)\end{array}$ & $\begin{array}{l}32.1 \\
(4.72)\end{array}$ & $\begin{array}{l}20.9 \\
(1.93)\end{array}$ \\
\hline$b$ & POLITICS & $\begin{array}{c}0.57 \\
(3.97)\end{array}$ & $\begin{array}{c}0.52 \\
(3.56)\end{array}$ & $\begin{array}{c}0.26 \\
(2.40)\end{array}$ & $\begin{array}{c}0.44 \\
(2.21)\end{array}$ \\
\hline$s_{e}$ & & $\begin{array}{c}0.05 \\
(3.38)\end{array}$ & $\begin{array}{c}0.06 \\
(3.06)\end{array}$ & $\begin{array}{c}0.06 \\
(2.12)\end{array}$ & $\begin{array}{c}0.08 \\
(1.82)\end{array}$ \\
\hline$s_{u}$ & & $\begin{array}{c}0.23 \\
(3.07)\end{array}$ & $\begin{array}{c}0.23 \\
(2.35)\end{array}$ & $\begin{array}{c}0.39 \\
(2.38)\end{array}$ & $\begin{array}{c}0.18 \\
(2.11)\end{array}$ \\
\hline Log-Likelihood & & 37.84 & 37.077 & 35.63 & 37.56 \\
\hline Akaike IC & & -63.68 & -62.15 & -59.26 & -63.12 \\
\hline Pr. Regime 1 & & 0.16 & 0.18 & 0.09 & 0.15 \\
\hline Pr. Regime 2 & & 0.35 & 0.27 & 0.09 & 0.05 \\
\hline Pr. Regime 3 & & 0.49 & 0.55 & 0.82 & 0.80 \\
\hline
\end{tabular}

Number of Observations: 46 


\section{APPENDIX III}

A potent criticism of ADA scores, despite their widespread use, is that they conflate votes in both the House and Senate and in different Congresses across time. A more accurate measure of true ideologies, it is argued, would correct for this problem and allow for more accurate intertemporal and interchamber comparisons. In an extremely useful 1999 paper, Groseclose, Levitt, and Snyder (GLS) derive transformations that translate a certain ADA score for a given year in a given chamber into an "adjusted" ADA score that allows for such comparisons.

We perform additional estimations using the GLS-adjusted ADA scores and generate the results shown in Tables A3 and A4. Similar to the results in Tables 1 and 2 above, these results illustrate the importance of the regime-switching methodology, since political constraints are significant in our maximum likelihood estimations but not in the linear models. In addition, the results exhibit the superiority of the F-V model and offer some support for the effectiveness of the CGK model. In general, the estimations with the adjusted ADA scores generate coefficients that are qualitatively similar to those produced from the "raw" ADA scores, adding robustness to the estimation.

\section{TABLE A3}

Linear Probability Models across Alternative Legislative Models Using Adjusted ADA Scores

( $\mathrm{t}$-statistics in parentheses)

\begin{tabular}{|c|c|c|c|c|}
\hline Variable & $\mathrm{F}-\mathrm{V}$ & CGK & MV & $\mathrm{PC}$ \\
\hline CONSTANT & $\begin{array}{l}15.98 \\
(2.62)\end{array}$ & $\begin{array}{l}16.92 \\
(2.49)\end{array}$ & $\begin{array}{l}11.33 \\
(1.68)\end{array}$ & $\begin{array}{l}12.58 \\
(1.85)\end{array}$ \\
\hline $\mathrm{SC}$ & $\begin{array}{c}0.68 \\
(7.00)\end{array}$ & $\begin{array}{c}0.69 \\
(6.64)\end{array}$ & $\begin{array}{c}0.69 \\
(7.19)\end{array}$ & $\begin{array}{c}0.67 \\
(6.93)\end{array}$ \\
\hline $\operatorname{Max}$ & $\begin{array}{c}-0.05 \\
(-0.30)\end{array}$ & $\begin{array}{c}0.01 \\
(0.11)\end{array}$ & $\begin{array}{c}0.04 \\
(1.02)\end{array}$ & $\begin{array}{c}0.05 \\
(0.84)\end{array}$ \\
\hline Min & $\begin{array}{c}0.24 \\
(0.94)\end{array}$ & $\begin{array}{c}0.04 \\
(0.15)\end{array}$ & $\begin{array}{c}-0.03 \\
(-0.56)\end{array}$ & $\begin{array}{c}0.07 \\
(0.91)\end{array}$ \\
\hline $\mathrm{R}^{2}$ & 0.58 & 0.57 & 0.58 & 0.59 \\
\hline F-statistic & 19.70 & 18.89 & 19.69 & 20.26 \\
\hline Standard Error & 0.09 & 0.09 & 0.09 & 0.09 \\
\hline Log-Likelihood & 48.95 & 48.39 & 48.94 & 49.33 \\
\hline
\end{tabular}


TABLE A4

The Econometric Model Using Adjusted ADA Scores

Maximum Likelihood Estimation

(t-statistics in parentheses)

\begin{tabular}{lccccc}
\hline Parameter & Variable & F-V & CGK & MV & PC \\
\hline \multirow{2}{*}{ CONSTANT } & -0.11 & -20.39 & -48.74 & -22.70 \\
& & $(-0.63)$ & $(-1.20)$ & $(-0.47)$ & $(-1.21)$ \\
$d$ & SC & 0.98 & 1.18 & 2.07 & 1.52 \\
& & $(2.37)$ & $(3.07)$ & $(0.76)$ & $(4.17)$ \\
$q$ & CONSTANT & 0.22 & 0.28 & 0.33 & 0.30 \\
& & $(1.94)$ & $(4.69)$ & $(2.19)$ & $(5.84)$ \\
$b$ & POLITICS & 0.82 & 0.66 & 0.34 & 0.40 \\
& & $(2.13)$ & $(3.68)$ & $(0.69)$ & $(5.00)$ \\
$s_{e}$ & & 0.07 & 0.06 & 0.07 & 0.09 \\
& & $(3.26)$ & $(3.28)$ & $(2.02)$ & $(9.54)$ \\
$s_{u}$ & & 0.06 & 0.10 & 0.13 & 0.01 \\
& & $(1.18)$ & $(2.05)$ & $(0.46)$ & $(1.74)$ \\
Log-Likelihood & & 51.41 & 48.99 & 49.45 & 46.10 \\
Pr. Regime 1 & & 0.17 & 0.17 & 0.06 & 0.17 \\
Pr. Regime 2 & & 0.11 & 0.21 & 0.08 & 0.10 \\
Pr. Regime 3 & & 0.72 & 0.62 & 0.86 & 0.73 \\
Number of Observations: 46 & & & & \\
\hline
\end{tabular}

\section{NOTES}

This paper was originally written while Spiller was a Visiting Scholar at the Center for the Study of Institutional Development at the Fundación Gobierno y Sociedad, Buenos Aires, which he thanks for financial support. Barak Richman thanks the John M. Olin Center for Law, Economics, and Business at Harvard Law School for its generous support. We would like to thank Jeffrey Segal for providing the data used in this paper and three anonymous referees for helpful comments.

1. In its applications to the external game faced by the justices, the strategic approach has been coined the "separation of powers" approach. See Eskridge 1991a.

2. Previous strategic approaches to judicial decision making can be found in Murphy's (1964) book on judicial strategy and in Dahl's (1957) suggestion that the selection process of Supreme Court justices caused judicial decisions to reflect the public's policy preferences since voters elected the judge-appointing politicians. See 
also Funston's (1975) analysis of the disagreements between the judicial and legislative branches during "change-over" periods of the Court.

3. The essence of strategic behavior is to consider the consequences of one's behavior on rivals' optimal behavior. In the sequential games commonly used in this literature, strategic behavior can be defined as maximizing behavior (with regard to policy preferences) that is forward-looking, in the sense of anticipating the possible actions by other policy makers. Supreme Court justices, in acting strategically, anticipate the subsequent actions of the Court's other justices ( "games within the Court") and of the other branches of government ("separation of power games").

4. That is, they vote their preferences sincerely. For a theoretical analysis of sincere voting as a dominant strategy within the court, and within groups in general, see Spiller and Spitzer 1992.

5. Spiller and Gely (1992) found that the Supreme Court was constrained by congressional policy preferences in labor-relations cases from 1949 to 1988. Holding Court composition constant, they determined that Court decisions became increasingly more liberal (conservative) as relevant members of Congress became more liberal (conservative).

6. Note, however, that Spiller and Tiller (1996) offer a model where the Court provokes a congressional reversal as a way to improve upon its policy outcome. In general, the strategic approach assumes that the Court can actually forecast which decisions would prompt Congress to act. Uncertain or unknown preferences are easily implementable. See, for example, Spiller 1992 or Schwartz, Spiller, and Urbiztondo 1994.

7. The figure assumes that the policy space can be represented by a single dimension corresponding to an ideological spectrum where, as in ADA ratings, the lower boundary represents the most extreme conservative policy and the upper boundary represents the most extreme liberal policy.

8. This model assumes symmetric preferences, an assumption typical of spatial models of this type. Also, although some investigators place the conservative end of a one-dimensional policy spectrum on the right side and place the liberal end on the left side, we use a different convention here. In later sections, we proxy legislative preferences with legislators' ADA ratings, which give higher values to liberal legislative records.

9. This result is a simple extension of the median voter to constrained environments. Since policy outcomes must fall within the legislative Pareto set, which is the range $[S, H]$ in Figure 1, justices vote for an outcome within $[H, S]$. In the figure, the preferred outcome for justices $A$ and $B$ within $[S, H]$ is $S$, but the preferred outcome for $C$ is $H$. Thus the median voter outcome is $S$.

10. The congressional Pareto set contains all possible policies for which a movement away from a policy in that set would make either the House or the Senate worse off. In other words, it comprises the entire set of policies that Congress would not be able to overturn. Conversely, all policies outside the Pareto set would be overturned by Congress and replaced with some other policy within the set.

11. The distinction between statutory and constitutional is not always clear. A single case can present the Court with both statutory and constitutional issues, and the Court has the discretion to base its decision in such a case on either grounds. Moreover, the Court's majority decision may rest on one type of argumentation (statutory or constitutional) while concurring justices may have preferred another. Segal (1997) preempts these selection complications by relying on the U.S. Supreme Court Judicial 
Database and defining as constitutional all cases "in which the authority the Court gave for its decision was judicial review at the national or state level" $(35, n$. 20). This method seems, to us at least, a useful and objective way to separate the two kinds of cases.

12. Segal's dataset does not include individual decisions but rather the percent of decisions each year that were pro-liberal. Thus, we cannot correct for individual case characteristics and individual ideologies must be translated into a tendency to cast proliberal votes in Supreme Court cases. The assumption we make in the text is intended to perform such a translation.

13. Alternatively, this measure could be interpreted as a preference for $60 \%$ of the Supreme Court's decisions to produce a pro-liberal outcome. We use this interpretation in the econometric model by averaging across a year.

14. Recall that the strategic model suggests that the Court's outcomes, in equilibrium, depend on a single political player, even if the relevant player is different across varying regimes. Our model begins analysis with the preferences of that decisive player. Note that the model operates within the probability space, not the actual liberal/ conservative nature of the Court's decision. Thus, the Court is seen as picking probabilities: although the Court picks for each case a pro-liberal or pro-conservative outcome, its preferences, and those of the other players, are characterized by averages. Consequently, the equilibrium probability is independent of actual policies, which would not be the case if preferences were characterized by each individual policy outcome.

15. We assume both that the identity of the critical player, $a$, remains constant throughout a given year and that her preferences remain constant through that year. Of course, there have been mid-year changes to both the membership of the Court and the membership of Congress (thus the difference between year $t$ and period $k$ ). These changes, however, are sufficiently infrequent and sufficiently inconsequential in changing the identity of the relevant member that assuming $P_{t a}$ to be constant should not affect our results.

16. To explore the robustness of our findings, we use alternative judicial ideological scores developed in Segal and Cover 1989 to further test the model. See Appendix II. For a discussion about the ADA ratings' "artificially extreme" bipolar distribution, see Snyder 1992. Also, see n. 28 of this article.

17. For a further discussion of the calculation of these constitutional scores, see Segal 1997, 35-36. Because these constitutional scores rely on votes that justices cast during their terms, we believe they may suffer from endogeneity. We review this issue further in the section discussing our dataset.

18. Segal claims his final calculated scores range from 5 to $93.3(1997,36)$, but his original data contain some predicted scores (for individual justices in particular years) that rise above 100 and some that dip below 0 . This fact is especially problematic since the $0-100$ spectrum is supposed to cover all possible ideologies; it calls into question the appropriateness of his method for calculating justices' ideologies. This error does not affect our results, however, since we use only the median justice's score, which is always within the $0-100$ range.

19. Because members of Congress vote on these issues, they are by nature nonconstitutional.

20. One could consider Segal's conflation of ADA and Supreme Court constitutional scores within the same dimension to be the flip side of his mistake in conflating 
ideological scores with policy outcomes. Segal directly compares ADA scores, Supreme Court constitutional scores, and policy outcomes to each other. In fact, a transformation is required to relate each one to the others.

21. Consider the following nonlinear transformation: call Segal's scores $S$, and let $S$ ' be a one-to-one nonlinear transformation of $S$ that also spans $0-100$. It is possible to find a transformation where $S^{\prime}<S$ for the interval $0-50$ and $S^{\prime}>S$ for the range 50-100. This transformation has the effect of making most $S^{\prime}$ ' closer to its extreme values. As a consequence, if we hold the congressional preferences constant, then the values arising from $S$ ' will tend to be closer to the boundaries of the congressional Pareto set than the values arising from $S$ will be. As we later discuss in detail, different transformations have very different implications for whether or not the strategic model is an appropriate representation of judicial decision making. Hence, the choice of transformation is crucial, and there is no reason why Segal's (1997) transformation is an appropriate one.

22. The transformation allows a direct comparison between the judicial ideological values and the ADA legislative scores. Furthermore, our approach avoids the problem of relying on a given value to reflect an essentially unobservable judicial ideology. Our model instead offers a probability distribution of ideal points for the Supreme Court along an ADA scale. See Spiller and Gely 1992 for a fuller discussion of constructing this latent variable.

23. Because the ADA ratings are constrained within the 0-100 range, the normality assumption of $u$ may not be appropriate. An alternative transformation of the left-hand-side variable could be designed but would not allow for a straightforward test of Segal's assumption of similarity between the two levels.

24. To see the bias formally, substitute, in the case of Regime 1 ( $S C>M a x)$, Equation (10) into (9). Rearranging terms yields the following equation: $P L=a+p$ * $M a x-p * S C_{i}+e$. Recall that justices in Regime 1 are more liberal than Congress and, according to the strategic approach, would cast votes at the most liberal end of the congressional Pareto set. The Max variable, which represents the most liberal endpoint, appropriately reflects the constraints imposed by Congress. Thus, under the strategic approach and for a justice in Regime 1, an increase in Max produces an increase in the probability of a liberal vote $P L$ when $S C$ is held constant. That is, if $P L$ were regressed on Max, then the coefficient $p$ would be positive and statistically significant. Yet the second variable, $S C_{i}$, which measures a justice's sincere preferences, is also in the regression equation and should not affect $P L$ because the sample is selected so that $S C$ exceeds Max. Since in the equation - and we arrive at this assertion by direct construction from (10)-Max and $S C_{i}$ share the same coefficient $p$, the regression would estimate a single value for the coefficient shared by the two variables even though they should generate coefficients of different values. The estimated parameter $p$ is an average between zero and the value of the coefficient that would be generated (in the case of a justice in Regime 1) if $P L$ were regressed only on the explanatory variable Max. Consequently, the regression biases the estimated parameter $p$ toward zero. A similar analysis shows that the same bias toward zero exists for Regime 2 .

25. The median voter theorem is indeterminate in terms of how each player votes. The theorem simply specifies that the median voter policy is the only equilibrium to the game, thus a majority must support it. Whether the outcome will be supported unanimously or by a large or thin majority is unspecified. Thus, we can only infer behavior by the median justice, who indeed must support the Court's decision. 
26. The Multiple Veto model, for example, produces Pareto sets that have both a lower boundary below zero and an upper boundary above 100 for 32 of the 46 years studied. If this model accurately depicted congressional behavior, then Congress would have been unable to overturn any Supreme Court decision, no matter how radical, for nearly two-thirds of all years after World War II. But one could say something even more striking: since these are essentially legislative models, they imply that Congress would be unable to legislate at all (at least over judiciary matters) during two-thirds of all such years, as any status quo would always fall in the gridlock area. Such a prospect seems not only unlikely but is factually wrong. The Party Caucus model is only slightly better at offering feasible Pareto sets, still yielding impossible Pareto sets for 27 of the 46 years. The Committee Gatekeeping model is a further improvement but generates impossible sets twice. The inadequacies of the legislative models explain Segal's observation that very few justices appear to be constrained from 1947 to 1992. We further find it unlikely that Congress and the individual justices share such ideological agreement - i.e., that so few justices would have policy preferences with which Congress would disagree. We note that a $0-100$ Pareto set would not imply gridlock in legislative issues where there is no identifiable status quo and where new legislation is a Pareto improvement for all of Congress.

27. In fact, he observes that his testing for political constraints is limited because so many justices in his analysis appear to be in Regime 3 . This pattern could simply be the result of the wrong assignment of regimes.

28. ADA measures are not without their faults. In particular, they are calculated from a small set of votes, they tend to use narrow majority votes, and a "no-vote" is equivalent to a vote in favor of the conservative position. They also have a bimodal distribution, which is at odds with other measurements of congressional preferences. See Snyder 1992. To address some of these criticisms, and to test the robustness of our findings, we also perform the empirical tests using adjusted ADA scores, as per Groseclose, Levitt, and Snyder 1999, which smooth ADA scores across time and chambers. See Appendix III.

29. We acknowledge some concern that these constitutional scores may be endogenous. Cases could be argued and decided on constitutional grounds, yet the decision might be influenced by congressional composition. Consequently, these constitutional scores may not be independent from congressional composition (see Spiller and Spitzer 1992). Spiller and Gely (1992) avoid this problem by using the percentage of Democrats on the Court as a proxy for Court preferences. While this tactic solves the problem of endogeneity, it yields a parameter that is not very precise. We consider Segal's (1997) constitutional scores to be strong, albeit imperfect, indices for the justices' ideologies. Although problems of endogeneity must be considered, and we still welcome future efforts to measure justices' ideologies, we proceed here with the constitutional scores for our analytical purposes.

Segal and Cover's scores (1989) are another innovative attempt to measure the justices' ideologies while avoiding the problem of endogeneity. Unfortunately, Epstein and Mershon (1996) have shown these scores to contain measurement error despite their assured independence and relative success in predicting decisions. Nonetheless, we also apply our econometric model to the Segal-Cover scores. See Appendix II.

30. With each justice's ideology being an unobserved latent variable, it is not straightforward to determine with certainty who the median justice is. Here, we implicitly 
assume that the constitutional scores capture the "right" order of justices. We also note that the proxy variable is not as precise as collecting data from the Court's actual decisions. Since, however, our aim is to use an improved technique with the data used by Segal (1997), we must remain committed to that dataset, which only contains proliberal votes for individual justices.

31. Our use of aggregate data does not mean we do not recognize that strategic behavior by political actors often varies from issue to issue. On the contrary, we predict that such "individualized" strategies have general, predictable trends, and aggregate data, while perhaps not adequate to characterize certain one-time behavior with great precision, should capture these tendencies sufficiently to test refutable hypotheses.

32. We used several starting values to be sure we obtained a good estimation. The Segal data are presented as annual averages. Thus, focusing on the median justices limits the available observations to 46 . Although in principle more observations are better than less, note that the model exclusively estimates six parameters, including standard deviations and constants. Thus, there are ample degrees of freedom, even for a switching-regime model. The robustness of the results presented here buttresses this point.

33. Recall that $d$ measures how a one-point increase in the Court's constitutional score affects its expected ideology in the ADA dimension. Similarly, $b$ measures how a one-point increase in the relevant player's ideology affects the probability of a proliberal Supreme Court decision.

34. This result is obtained from the estimated values for the coefficient, $b$, shown in Table 2. A value of 0.66 , for example, means that a 10 -point increase in the decisive player's ideological score translates into a $6.6 \%$ increase in the pro-liberal percent of annual Court decisions.

35. To have a preliminary test of the robustness of the results, we developed analogous maximum likelihood regressions using the Segal-Cover scores of the Supreme Court preferences. These additional estimations, shown in Appendix II, illustrate that the main qualitative results persist when using an alternative set of scores for justices' ideologies.

36. We obtain these results from the estimated probabilities for Regimes 1,2, and 3 , shown in Table 2.

37. The interval $\left[\overline{S C}-2 s_{u}, \overline{S C}+2 s_{u}\right]$ is also plotted, where $s_{u}$ is the standard deviation of $u$. This step is to capture the likely range of values for $\overline{S C}$.

38. In the 1950s and late 1970s through 1980s, the Court's estimated ideological score was close to the conservative boundary of the Congressional Pareto set, so the probability of actually being constrained was higher then than during the 1960s and 1970s.

39. The resulting estimation for the constant $g$ is more difficult to interpret, however. It is estimated to be -12.8 , which is far from zero, but that value is not statistically significant.

40. The other models, though, provide less support for this result.

41. The chi-square test with two degrees of freedom has the following values for $.10, .05$, and 0.01 significance levels: 4.605, 5.991, and 9.21 . 


\section{REFERENCES}

Akaike, Hirotsugu. 1974. "A New Look at the Statistical Model Identification." IEEE Transaction on Automatic Control AC-9, 716-23.

Chi, P., and C.T. Russell. 1999. Statistical Methods for Data Analysis in Space Physics. Computer Based Learning Unit, University of Leeds, West Yorkshire, England.

Dahl, Robert A. 1957. "Decision-Making in a Democracy: The Supreme Court as a National Policy-Maker." Journal of Public Law 6:179-295.

Epstein, Lee, and Jack Knight. 1995. "Positive Approaches to Supreme Court Decision Making." Presented at the annual meeting of the Midwest Political Science Association, Chicago.

Epstein, Lee, and Jack Knight. 1998. The Choices Justices Make. Washington: CQ Press. Epstein, Lee, and Carol Mershon. 1996. "Measuring Political Preferences." American Journal of Political Science 40:261-94.

Epstein, Lee, and Thomas G. Walker. 1995. "The Role of the Supreme Court on American Society: Playing the Reconstruction Game." In Contemplating Courts, ed. Lee Epstein. Washington, DC: CQ Press.

Eskridge, William N., Jr. 1991a. "Overriding Supreme Court Statutory Interpretation Decisions." Yale Law Journal 101:825-41.

Eskridge, William N., Jr. 1991b. "Reneging on History? Playing the Court/Congress/ President Civil Rights Game.” California Law Review 79:613-84.

Funston, Richard. 1975. "The Supreme Court and Critical Elections." American Political Science Review 69:795-811.

Gely, Rafael, and Pablo T. Spiller. 1990. "A Rational Choice Theory of Supreme Court Statutory Decisions with Applications to the State Farm and Grove City Cases." Journal of Law, Economics, and Organization 6:263-300.

Groseclose, Timothy, Steven D. Levitt, and James M. Snyder, Jr. 1999. "Comparing Interest Group Scores across Time and Chambers: Adjusted ADA Scores for the U.S. Congress." American Political Science Review 93:33-50.

Harvey, Andrew C. 1981. Time Series Models. New York: Wiley.

Krehbiel, Keith. 1998. Pivotal Politics: A Theory of U.S. Lawmaking. Chicago, IL: University of Chicago Press.

Marks, Brian A. 1988. "A Model of Judicial Influence on Congressional Policymaking: 'Grove City College v. Bell.’” Working Paper in Political Science P-88-7, Hoover Institution.

Murphy, Walter F. 1964. Elements of Judicial Strategy. Chicago, IL: University of Chicago Press.

Pritchett, C. Herman. 1941. "Divisions of Opinion among Justices of the Supreme Court, 1939-1941." American Political Science Review 35:890-98.

Pritchett, C. Herman. 1948. "The Roosevelt Court: Votes and Values." American Political Science Review 42:53-67.

Schubert, Glendon A. 1965. The Judicial Mind: The Attitudes and Ideologies of Supreme Court Justices, 1946-1963. Evanston, IL: Northwestern University Press.

Schwartz, Edward P. 1992. "Policy, Precedent, and Power: A Positive Theory of Supreme Court Decision-Making." Journal of Law, Economics, and Organization 8:219-52. 
Schwartz, Edward P., Pablo T. Spiller, and S. Urbiztondo. 1994. "A Positive Theory of Legislative Intent." Law and Contemporary Problems 57:51-74.

Segal, Jeffrey A. 1997. "Separation-of-Powers Games in the Positive Theory of Congress and Courts." American Political Science Review 91:28-44.

Segal, Jeffrey A., and Albert D. Cover. 1989. "Ideological Values and the Votes of U.S. Supreme Court Justices." American Political Science Review 83:557-65.

Segal, Jeffrey A., Lee Epstein, Charles M. Cameron, and Harold J. Spaeth. 1995. "Ideological Values and the Votes of U.S. Supreme Court Justices Revisited." Journal of Politics 57:812-23.

Segal, Jeffrey A., and Harold J. Spaeth. 1993. The Supreme Court and the Attitudinal Model. New York: Cambridge University Press.

Segal, Jeffrey A., and C-L. Wang. 2001. "Inducing Apparently Strategic Behavior in Models of Bounded Discretion: The Case of Regime-Change Switching Regressions." Presented at the annual meeting of the American Political Science Association, San Francisco.

Snyder, James M., Jr. 1992. "Committee Power, Structure-Induced Equilibria, and Roll Call Votes." American Journal of Political Science 36:1-30.

Spiller, Pablo T. 1992. "Agency Discretion under Judicial Review." Mathematical and Computer Modeling 16:185-200.

Spiller, Pablo T. 1996. "A Positive Political Theory of Regulatory InstrumentsContracts, Administrative Law or Regulatory Specificity." Southern California Law Review 69:477-515.

Spiller, Pablo T., and Rafael Gely. 1992. "Congressional Control or Judicial Independence: The Determinants of U.S. Supreme Court Labor-Relations Decisions, 1949-1988." Rand Journal of Economics 23:463-92.

Spiller, Pablo T., and Matthew L. Spitzer. 1992. "Judicial Choice of Legal Doctrines." Journal of Law, Economics, and Organization 8:8-46.

Spiller, Pablo T., and Emerson H. Tiller. 1996. "Invitations to Override: Congressional Reversals of Supreme Court Decisions." International Review of Law and Economics 16:503-21. 